\title{
Tendências no Desenvolvimento de Gases de Proteção Utilizados na Soldagem MIG/MAG
}

\author{
(Trends in the Development of Protective Gases Used in GMAW Welding)
}

\author{
Luiz Claudio Soares Tatagiba', Renata Barbosa Gonçalves ${ }^{2}$, Ronaldo Paranhos ${ }^{2}$ \\ IPETROBRAS, US-SUB/EQSB/MEQS, Macaé, RJ, Brasil, luiztatagiba@petrobras.com.br \\ ${ }^{2} U E N F$, LAMAV, Campos dos Goytacazes, RJ, Brasil, renatahaa@gmail.com, paranhos@uenf.br
}

\begin{abstract}
Resumo
Este trabalho tem como objetivo apresentar uma revisão do estado da arte sobre os gases de proteção usados nos processos de soldagem a arco elétrico, com ênfase na soldagem MIG/MAG do aço. São apresentados os principais conceitos da física do arco e as propriedades relacionadas aos gases de proteção. O modelo de atmosfera ligeiramente oxidante para os gases de proteção é discutido, sendo mostradas as formulações dos gases estudados em artigos científicos e em patentes depositadas, bem como as reivindicações (vantagens) requeridas. Também são mencionados alguns poucos estudos usando adições de gases não convencionais. Foi observado que no desenvolvimento de gases de proteção para soldagem MIG/MAG do aço predomina o modelo da formação de atmosfera ligeiramente oxidante. A maioria das formulações propostas envolve o uso de misturas binárias, ternárias e até quaternárias dos gases $\mathrm{Ar}, \mathrm{He}, \mathrm{CO}_{2}$ e $\mathrm{O}_{2}$. Em aplicações especificas, adições de $\mathrm{N}_{2}$ e $\mathrm{H}_{2}$ foram usadas. Neste sentido, pouca inovação foi identificada, sendo atribuídas possíveis razões a este fato. A tendência observada para o desenvolvimento de gases de proteção parece ser o uso de misturas ricas em gases inertes, com adições calibradas de elementos oxidantes, sempre atendendo a aplicações especificas.
\end{abstract}

Palavras-chave: Gás de proteção, Soldagem MIG-MA, Física do arco.

\begin{abstract}
This paper has as objective to present a state of the art review on the shielding gases used in the electric arc welding processes, with emphasis on GMAW welding of steel. There are shown the main concepts of arc physics and properties related to shielding gases. The model of slightly oxidizing atmosphere for shielding gases is discussed, and the formulations of the gases studied in scientific articles and in deposited patents, as well as the claims (benefits) required. It also mentions some few studies using additions of non-conventional gases. It was observed that for the development of shielding gases for the GMAW steel welding the model of slightly oxidizing atmosphere is predominant. Most of proposed formulations involve the use of binary, ternary or even quaternary mixtures of the gases $\mathrm{Ar}, \mathrm{He}, \mathrm{CO}_{2}$ and $\mathrm{O}_{2}$. For specific aplications, additions of $\mathrm{N}_{2}$ e $\mathrm{H}_{2}$ were used. In this meaning, few innovations were identified, and possible reasons were attributed. The trend observed for the development of shielding gases seems to be the use of mixtures rich in inert gases, with calibrated additions of oxidizing elements, always looking for specific applications.
\end{abstract}

Key-words: Shielding gas, GMAW welding, Arc physics.

\section{Gases de Proteção na Soldagem}

A soldagem a arco com proteção gasosa, com ênfase no processo MIG/MAG, é atualmente utilizada em incontáveis aplicações industriais. A facilidade de automação e os diversos tipos de materiais que podem ser soldados por este método ampliam ainda mais as suas aplicações. São grandes usuários deste processo de fabricação a indústria automotiva e de autopeças, alimentícia, construção civil, fabricação de bens de consumo, estaleiros, caldeirarias, implementos agrícolas, botijões de gás, entre tantas outras.

O gás de proteção na soldagem a arco tem como finalidade básica proteger a poça de fusão contra os efeitos nocivos

(Convidado em 15/05/2012; Texto final em 05/09/2012). do oxigênio contido no ar atmosférico, que associado às características da fonte de energia e aos metais de adição, pode ajudar na melhoria da qualidade, do funcionamento e da produtividade na soldagem de aços, aços inoxidáveis, ligas de alumínio, entre outras aplicações. O gás pode ser inerte, que não têm praticamente nenhuma solubilidade na maioria dos metais, ativo, ou uma mistura destes dois tipos. Segundo a sua natureza e composição estes terão uma influência preponderante nas características do arco e no tipo de transferência metálica, na velocidade de soldagem, na perda por projeção (respingos), na penetração e no formato do cordão de solda, e, ainda, no custo final da operação de soldagem. São atribuídas também ao tipo de gás empregado as perdas de elementos químicos, a temperatura da poça de fusão, a sensibilidade à fissuração e porosidade, bem como a facilidade na execução da soldagem em diversas posições.

A escolha do tipo de atmosfera protetora para soldagem depende de fatores como custo, facilidade de manuseio, 
efeitos fisiológicos sobre as pessoas, geração de fumos e gases, estabilidade a temperaturas elevadas, entre outros. A solubilidade do gás no metal fundido que se quer proteger durante a soldagem, também deve ser observada, pois se uma quantidade substancial do gás entra no metal fundido pode causar liberação do gás durante a solidificação causando descontinuidades na solda produzida, como por exemplo, porosidade.

Os gases de proteção utilizados amplamente nas últimas décadas em soldagem do aço carbono são o argônio (Ar), o dióxido de carbono $\left(\mathrm{CO}_{2}\right)$ e o hélio (He), que são usados puros ou misturados entre si. Em alguns casos, pequenas quantidades de oxigênio $\left(\mathrm{O}_{2}\right)$ são misturadas aos anteriores. Adições de elementos redutores como o hidrogênio $\left(\mathrm{H}_{2}\right)$ e o nitrogênio $(\mathrm{N})$ são citadas na soldagem de aços inoxidáveis e outras aplicações específicas. $\mathrm{Na}$ indústria, embora sejam disponíveis misturas binárias, ternárias e até quaternárias, as mais populares são ainda à base de $\mathrm{Ar}$ e $\mathrm{CO}_{2}$. A utilização do gás de proteção adequado garante a eficiência da deposição da solda e o custo, sendo o hélio $(\mathrm{He})$ o gás mais caro, o Ar de preço intermediário e o $\mathrm{CO}_{2}$ o mais barato [1].

Este trabalho apresenta os aspectos teóricos mais relevantes sobre os gases de proteção utilizados em soldagem a arco correlacionando estes conhecimentos às exigências operacionais deste processo de fabricação. Através de um levantamento sobre os avanços encontrados, a partir de dados obtidos em artigos científicos e patentes depositadas, se espera mostrar que atmosferas levemente oxidantes são as mais empregadas na soldagem do aço bem como suas principais características e teores desejáveis nas misturas e a sua relação com a melhoria do processo de soldagem no que se refere ao aumento da taxa de deposição, da velocidade de soldagem e estabilidade no processo de soldagem.

\section{Aspectos Teóricos Relevantes}

Dentre as fontes de calor empregadas em soldagem, o arco elétrico é a mais utilizada. Em soldagem de materiais metálicos a soldagem a arco apresenta vantagens que justificam a sua utilização, entre elas: concentração de energia suficiente para a fusão localizada, facilidade de controle, baixo custo e um nível aceitável de riscos aos operadores. A pequena região do espaço em que o arco elétrico está compreendido possui elevadas temperaturas, forte radiação luminosa e ultravioleta, intenso fluxo de matéria e grandes variações de propriedades físicas [2].

A produção do arco é proveniente da emissão de elétrons em quantidade satisfatória para sustentar a corrente no arco, ou seja, a condução elétrica no arco é devida quase totalmente a este processo. A alta temperatura do gás de proteção na região da solda promove choques intensos de seus componentes, que tem como consequência a ionização do gás no arco de soldagem.

As propriedades físicas e químicas dos gases como potencial de ionização, condutividade térmica, potencial de oxidação e tensão superficial, entre outras, definem as principais características operacionais do arco de soldagem e as propriedades das soldas. Variações dos parâmetros de soldagem como tensão e corrente, entre outros, modifica a geometria do cordão de solda, e são intensamente influenciados pela composição química do gás de proteção [3].

\subsection{Potencial de Ionização}

Para a manutenção do arco elétrico durante a soldagem, é necessário que partículas carregadas eletricamente estejam no espaço consistido entre o eletrodo e a peça. Devido ao aquecimento do gás ocorre o aumento da energia de suas moléculas, provocando principalmente o movimento e vibração. Em temperaturas elevadas esta energia vibracional das moléculas poliatômicas atinge níveis bastante altos, causando a ruptura ou dissociação em átomos. Como exemplo, pode ser observado à dissociação da molécula do $\mathrm{O}_{2}$ que pode ser representada conforme abaixo $[4,5]$.

$$
\mathrm{O}_{2} \rightarrow 2 \mathrm{O} \text { (dissociação) } \quad \text { eq. } 1
$$

Na dissociação ocorrem reações endotérmicas que absorvem energia, pois a entalpia dos produtos é maior que a dos reagentes. O balanço entre a variação de entalpia e de entropia da reação tem como resultado a variação da energia livre ou energia livre de Gibbs - $\Delta \mathrm{G}$ [6]. Já próximo a região da solda quando os átomos dissociados reagem com eles mesmos ou com os elementos do metal fundido o processo é exotérmico, pois libera energia e provoca o aumento da entropia levando a diminuição da energia livre do sistema $-\Delta G<0$ [7].

A ionização ocorre após a dissociação em temperaturas mais elevadas ainda quando elétrons das camadas mais externas dos átomos podem ser expulsos. Os choques destes elétrons em alta velocidade provocam a ionização. Em temperaturas mais elevadas que as que provocam a ionização mais elétrons podem ser expulsos, acontecendo ionização múltipla. A ionização simples de um átomo dissociado é representada a seguir.

$$
\mathrm{O} \rightarrow \mathrm{O}^{+}+\mathrm{e}^{-} \text {(ionização) } \quad \text { eq. } 2
$$

A fração das moléculas do gás que são dissociadas e a fração de átomos do gás que são ionizados crescem exponencialmente com o aumento da temperatura na coluna de plasma do arco elétrico. Há também uma forte influência da energia livre de dissociação e do primeiro estágio de ionização na dissociação e na ionização do gás, respectivamente [2].

Potencial de ionização pode ser definido como a energia total em elétron volts $(\mathrm{eV})$ necessária para retirar o elétron, com menor força de ligação, da camada de valência de um átomo ou molécula que em uma distância infinita estará em repouso [8].

O potencial de ionização é uma propriedade importante dos elementos presentes no arco elétrico de soldagem, formada por uma atmosfera complexa devido aos gases de proteção e metais em estado de vapor. A abertura do arco, a capacidade do arco em conduzir corrente elétrica e a sua estabilidade são determinados de acordo com a facilidade de ionização destes materiais [4,5].

\subsection{Condutividade Térmica}

A propriedade física de condutividade térmica do gás de proteção ionizado está relacionada com a quantidade de calor 

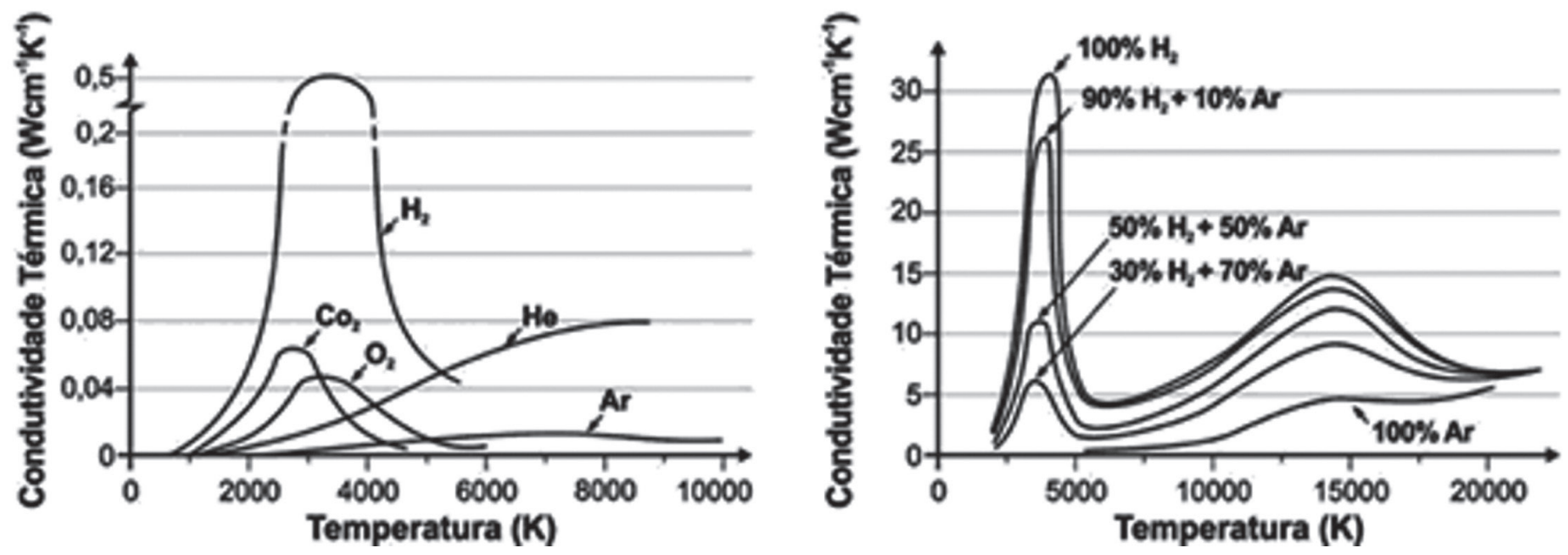

Figura 1. Condutividade térmica de alguns gases em função da temperatura [10].

transferido, pelo choque das partículas existentes, na coluna de plasma. Ela vai influenciar expressivamente na transferência metálica e no perfil de penetração do cordão na soldagem pelo processo GMAW [9].

A Figura 1 (a) mostra a condutividade térmica em função da temperatura para diversos gases, onde se observa que a condutividade térmica do He é maior que a do $\mathrm{Ar}$, e a do $\mathrm{H} 2$ se sobressai às duas. Já a Figura 1 (b) mostra a condutividade térmica total para algumas misturas $\mathrm{Ar}-\mathrm{H} 2$, onde se observa que a condutividade térmica do $\mathrm{H} 2$ é significativamente superior à do $\operatorname{Ar}$ [10]. As figuras 1 (a) e (b) mostram um pico nesta propriedade para a faixa de temperatura entre 3000 e $4500 \mathrm{~K}$, atribuído à dissociação do gás.

Dentre os gases de proteção utilizados no processo GMAW, por exemplo, o argônio é o gás que apresenta menor condutividade térmica para qualquer faixa de temperatura na atmosfera do arco [9]. A Tabela 1 mostra o potencial de ionização (PI) e a condutividade térmica (CT) de gases utilizados normalmente em proteção na soldagem a arco elétrico.

Tabela 1. Potencial de ionização e condutividade térmica de gases de proteção do arco elétrico em soldagem [11].

\begin{tabular}{|c|c|c|c|}
\hline Gás & $\begin{array}{c}\text { Símbolo } \\
\text { químico }\end{array}$ & $\mathrm{PI}(\mathrm{eV})$ & $\mathrm{CT}(\mathrm{mW} / \mathrm{m} . \mathrm{K})$ \\
\hline Argônio & $\mathrm{Ar}$ & 15,8 & 16,4 \\
\hline Dióxido de carbono & $\mathrm{CO}_{2}$ & 14,4 & 14,7 \\
\hline Hélio & $\mathrm{He}$ & 24,6 & 142,6 \\
\hline Hidrogênio & $\mathrm{H}_{2}$ & 13,5 & 168,3 \\
\hline Nitrogênio & $\mathrm{N}_{2}$ & 14,5 & 24,0 \\
\hline Oxigênio & $\mathrm{O}_{2}$ & 13,2 & 24,2 \\
\hline
\end{tabular}

\subsection{Potencial de Oxidação}

O potencial de oxidação (PO) pode ser definido como a capacidade do gás de proteção oxidar um metal durante a soldagem. Os gases $\mathrm{CO}_{2}$ e $\mathrm{O}_{2}$, quando presentes no gás de proteção, aumentam o conteúdo de oxigênio no metal de solda e o PO varia com a porcentagem volumétrica dos mesmos na mistura. O PO do $\mathrm{CO}_{2}$ em misturas gasosas pode ser considerado como a metade do potencial de oxidação do $\mathrm{O}_{2}$ quando este é empregado. Isto explica o emprego de misturas comerciais de argônio com baixos teores de $\mathrm{O}_{2}$ em relação ao $\mathrm{CO}_{2}$. Adições de oxigênio comumente são restringidas a no máximo $8 \%$ na mistura, para garantir benefícios operacionais [12].

$\mathrm{A}$ adição de $\mathrm{O}_{2}$ em misturas gasosas apresenta como desvantagem o aumento dos respingos, provocados pela constrição do arco que se torna instável pela ação do resfriamento. A causa do resfriamento é a reação endotérmica induzida pela decomposição térmica das moléculas de oxigênio [13].

$\mathrm{O}$ gás $\mathrm{CO}_{2}$ pode ser considerado insolúvel no aço fundido, sendo amplamente usado em inúmeros processos de soldagem. Porém em soldagem com este gás podem ocorrer algumas perdas de elementos oxidáveis em ligas de aço. Considera-se que o monóxido de carbono oferece maior proteção contra a oxidação, porém, além de ser tóxico, em muitas circunstâncias poderia carbonizar o ferro e o aço [8].

Entretanto, sobre a poça de fusão pode haver $\mathrm{CO}_{2}$ não dissociado juntamente com $\mathrm{CO}, \mathrm{O}$ e $\mathrm{O}_{2}$ (recombinaçã̃o de oxigênio monoatômico). $\mathrm{O}$ gás $\mathrm{CO}_{2}$ é uma fonte de carbono e oxigênio quando dissociado no arco elétrico. O potencial de oxidação (PO) deste gás pode ser estimado conforme abaixo [14], onde $\mu$ é o fator oxidante que comumente é estimado em $1 / 2$.

$\mathrm{PO}=\mathrm{O}_{2}+\mu \mathrm{CO}_{2} \quad$ eq. 3

Em gases e misturas gasosas oxidantes, como por exemplo, $\mathrm{CO}_{2}, \mathrm{Ar}+\mathrm{CO}_{2}, \mathrm{CO}_{2}+\mathrm{O}_{2}$, utilizados em soldagem, se observa uma perda significativa de elementos de liga e impurezas no metal fundido devido à interação com o oxigênio. A oxidação do metal pelo gás de proteção depende da composição de ambos e dos parâmetros de soldagem aplicados [15]. 


\subsection{Tensão Superficial}

A definição de tensão superficial é de uma força agindo por unidade de comprimento numa superfície líquida cuja unidade no Sistema Internacional (SI) é N/m. As forças de tensão superficial influenciam na transferência do metal líquido do eletrodo para o metal de base e também na formação e na fluência da poça de fusão, tornando esta propriedade de grande importância na soldagem por fusão [4].

O conceito de tensão superficial do metal em superfícies que se irá unir está associado à dissolução do metal de adição na união metalúrgica com o metal base [5]. A tensão superficial em soldagem depende das interações físico-químicas que acontecem entre o metal de adição fundido e a poça de fusão, ou com o metal base [16].

Na soldagem pelo processo GMAW a transferência metálica por curto-circuito é a mais usual. Neste modo operacional a transferência de metal ocorre basicamente por tensão superficial quando a gota toca o metal líquido da poça de solda. Os parâmetros que influenciam a transferência por curto-circuito são a tensão de soldagem, indutância e o gás de proteção. Por outro lado o gás de proteção modifica a transferência metálica devido à influência no comprimento do arco e na tensão superficial do metal líquido [17].

A adição de $\mathrm{O}_{2}$ ao Ar, na soldagem do aço carbono, com transferência por curto-circuito, em quantidades apropriadas, influencia na redução do tamanho da gota no arco devido à redução da tensão superficial e aumenta sua taxa de transferência [18].

Na transferência globular, os parâmetros de soldagem são maiores do que por curto-circuito. $\mathrm{O}$ arco é contínuo, mas a transferência é irregular e um tanto ineficiente. A penetração é limitada, o cordão tem uma aparência irregular e quantidades excessivas de respingos, este tipo limita-se a posições plana ou horizontal. Na transferência por spray os parâmetros de soldagem são maiores dos da transferência globular. A poça de solda gerada é muito fluida, limitando esta transferência para soldagem em posições plana ou horizontal [19].

\section{Modelo Oxidante de Atmosfera Gasosa}

A interação dos metais e suas ligas com o meio ambiente provoca a oxidação. Isto pode ser explicado pela transferência de elétrons do elemento redutor para o elemento oxidante em seus níveis eletrônicos livres. Esta combinação é tanto maior quanto maior a temperatura, particularmente quando no estado fundido, como é o caso de uma operação de soldagem. Os metais são encontrados na natureza em forma de óxidos devido à particularidade de deslocamento de elétrons, característica da ligação atômica metálica [20].

O modelo oxidante de atmosfera gasosa se aplica na soldagem MIG/MAG dos aços. De acordo com este modelo, filmes de óxidos com espessura microscópica, existentes na superfície do cátodo $(+)$, região entre a coluna de plasma e a peça a ser soldada, têm uma importância essencial na emissão de elétrons. Os elétrons são emitidos por camadas de óxidos, que naturalmente tem ligações eletrônicas mais fracas que a do metal de base, existentes sobre a poça fundida e nas redondezas. Este fenômeno é chamado de emissão catódica e tem como explicação que a tensão localizada criada entre esta camada e o metal de base proporciona o agrupamento e aceleração dos elétrons em direção ao anodo (-), região do arco compreendido entre a coluna de plasma e eletrodo consumível. A tensão entre o eletrodo e a peça não é muito alta e como consequência da aceleração dos elétrons a camada de óxido é atravessada e removida provocando o deslocamento dos elétrons pela coluna de plasma até o anodo [11].

$\mathrm{Na}$ soldagem de aços pelo processo MIG/MAG, quando as camadas de óxido próximas da poça de fusão são consumidas, o arco tende a se desviar para longe desta, em busca de novas regiões que possuam filmes óxidos para a emissão de elétrons. Este efeito pode reduzir a estabilidade do arco. Para que a camada de óxido seja regenerada suprimindo este efeito, é feita a adição de gases oxidantes $\left(\mathrm{O}_{2}\right.$ ou $\left.\mathrm{CO}_{2}\right)$ na mistura de proteção, ou seja, o PO do gás de proteção é uma propriedade de grande importância na soldagem MIG/MAG dos aços $[2,11]$. Na soldagem de metais altamente oxidáveis, como o $\mathrm{Al}, \mathrm{Mg}$ e Ti, a adição de gases oxidantes não é necessária.

Além de gás oxidante existe também gás redutor que tem como característica proteção do metal aquecido da oxidação como também redução de qualquer óxido que possa estar na superfície do metal. Podem ser citados o hidrogênio $\left(\mathrm{H}_{2}\right)$ e o nitrogênio $\left(\mathrm{N}_{2}\right)$ como gases redutores. Porém os gases redutores na soldagem pelo processo MIG/MAG se comportam como gases inertes quando a estabilidade do arco é avaliada [11].

\subsection{Elementos Desoxidantes no Metal de Adição}

O uso de um gás de proteção levemente oxidante para a soldagem dos aços traz a necessidade do uso de elementos desoxidantes no metal de adição, como o manganês $(\mathrm{Mn})$ e o silício ( $\mathrm{Si})$. Os teores corretos de Mn e Si são de fundamental importância para o resultado da soldagem pelo processo MIG/ MAG de aços carbono. O Mn e o Si tem a função de desoxidar a poça de fusão, pois em contato com o $\mathrm{O}_{2}$ formam óxidos que se alojam na superfície do cordão de solda que são removidos posteriormente. $\mathrm{O}$ gás de proteção deve ter um $\mathrm{PO}$ adequado, pois se for baixo não ocorrerá à formação de óxidos superficiais, com o excesso destes elementos de liga formando solução sólida substitucional, endurecendo o metal de solda. Logo, a seleção do metal de adição deve ser considerada em conjunto com o gás de proteção. Uma solda com pouca ou nenhuma escória pode sugerir um arame com baixo teor desoxidante e um gás com baixo PO, ou um arame com baixo teor de desoxidante e um gás com alto $\mathrm{PO}$ que pode provocar porosidade e propriedades mecânicas indesejáveis na solda.

\subsection{Consequências do Excesso de Oxigênio no Gás de Proteção}

Se, por um lado, de acordo com a teoria do modelo oxidante, é necessária a presença de algum elemento oxidante para a estabilidade do arco elétrico, o excesso de oxigênio é prejudicial à soldagem. De fato, o oxigênio tem elevada solubilidade no ferro 
líquido e muito baixa solubilidade no ferro sólido. Embora a taxa de formação de óxido em soldagem varie consideravelmente de metal para metal, uma fina camada de óxido pode impedir a soldagem de peças e outros problemas podem surgir como, por exemplo [8]:

- As gotas fundidas a partir do metal de adição podem se oxidar durante a transferência para a poça de fusão e não aderirem ao metal de solda;

- Os óxidos formados podem se dissolver no metal fundido provocando a fragilização da solda no estado sólido;

- A quantidade de óxidos aprisionados em uma solda pode diminuir expressivamente suas propriedades mecânicas.

- A adição de $\mathrm{O}_{2}$ na mistura gasosa de proteção provoca a perda de elementos químicos, pela oxidação que se intensifica quanto maior o teor deste gás na mistura.

Misturas gasosas com elevado teor de $\mathrm{O}_{2}$ produzem soldas com tenacidade ao impacto reduzida devido à formação de inclusões no metal de solda que atuam como concentradores de tensão e de propagação de trincas.

Por outro lado, aumentando o teor de oxigênio na solda aumenta sua resistência. Baixos teores de $\mathrm{CO}_{2}$ e $\mathrm{O}_{2}$ no gás de proteção geram quantidades aceitáveis de inclusões de óxidos, tornando a microestrutura mais refinada e favorecendo uma melhor resistência ao impacto [21].

O oxigênio dissolvido na poça de fusão além de causar inclusões de óxidos também reage com o carbono presente no aço, desde que tenha quantidade suficiente deste gás. Nesta reação com o carbono há a produção de $\mathrm{CO}$ ou $\mathrm{CO}_{2}$ que provoca porosidades na solda produzida e também influencia na redução da qualidade das propriedades mecânicas do cordão [22].

\section{Principais Formulações de Gases Formadores de Atmosfera Oxidante}

Como vêm sendo explicitado neste trabalho, as formulações dos gases para proteção em operações de soldagem também têm o objetivo de promover um arco estável. Esta estabilidade é associada aos mecanismos de emissão de elétrons no arco elétrico [23]. A estabilidade do arco pode ser medida pelas flutuações no comprimento do arco, variações na tensão e na corrente, e pela natureza da forma de transferência metálica do arco. Devido à ausência de compostos de escórias reativas, que resultariam do gás de proteção pode ocorrer ou não uma perda mínima em elementos metálicos assim como a necessidade da remoção de escória [24].

Encontra-se inicialmente a aplicação de He como gás de proteção, e posteriormente a introdução de $\mathrm{Ar}$ e do $\mathrm{CO}_{2}$. As especificidades de cada gás individual estimularam no início de 1970 a utilização das misturas de gases [25]. Atualmente ainda pode ser observada a existência de muita pesquisa nesta área, seja com a publicação de artigos científicos ou com o requerimento de patentes.

Visando orientar as aplicações de gases em misturas para proteção em processos de soldagem, em 1997 a Sociedade Americana de Soldagem (AWS - American Welding Society) publicou a norma AWS A5.32M [26]. A segunda edição desta norma foi feita em 2011 e agrupa os gases e misturas de gás para soldagem por fusão e processos afins.

Na Tabela 2, são listadas composições do gás de proteção e um resumo dos resultados alcançados, utilizados em trabalhos científicos e requeridos em patentes. A seguir, comentários são feitos.

Tabela 2. Formulações de gás de proteção para soldagem a arco elétrico.

\begin{tabular}{|c|c|c|c|c|}
\hline Ano & Ref. & \multicolumn{2}{|c|}{ Gás de Proteção } & Resultados \\
\hline 1960 & [24] & \multicolumn{2}{|c|}{$\begin{array}{c}\mathrm{Ar} / \mathrm{He} \\
1-20 \% \mathrm{CO}_{2} / \mathrm{CO}\end{array}$} & $\begin{array}{l}\text { Material: aço carbono }(<0,35 \% \mathrm{C}) \text {. Obtenção de um cordão de solda muito liso e } \\
\text { uniforme. Particularmente quando é adicionado } \mathrm{CO}_{2} \text { à mistura. }\end{array}$ \\
\hline 1964 & [27] & \multicolumn{2}{|c|}{$\begin{array}{l}\mathrm{Ar} \text { e/ou } \mathrm{He} \\
20-70 \% \mathrm{CO}_{2} / \mathrm{CO} \\
1-15 \% \mathrm{O}_{2}\end{array}$} & $\begin{array}{l}\text { Material: aço carbono. Formação de uma poça de solda que associa a boa penetração } \\
\text { fornecida pelo gás } \mathrm{CO}_{2} \text { com a boa largura de cordão fornecia pelo Ar. }\end{array}$ \\
\hline 1970 & [28] & $\begin{array}{l}\mathrm{He} \\
40-60 \% \mathrm{Ar} \\
1-15 \% \mathrm{CO}_{2}\end{array}$ & $\begin{array}{l}\mathrm{Ar} \\
1-15 \% \mathrm{CO}_{2} \\
60-80 \% \mathrm{He}\end{array}$ & $\begin{array}{l}\text { Material: aço carbono. Possibilidade de realizar soldas em todas as posições, } \\
\text { obtendo adequadas propriedades de resistência mecânica e tenacidade. }\end{array}$ \\
\hline 1986 & [29] & \multicolumn{2}{|c|}{$\begin{array}{c}65-95 \% \mathrm{He} \\
1,75-2,25 \% \mathrm{CO}_{2} \\
0,25-1 \% \mathrm{O}_{2} \\
\end{array}$} & Material: aço carbono. Solda livre de escória e com uma superfície mais limpa. \\
\hline 1989 & [30] & \multicolumn{2}{|c|}{$\begin{array}{l}\mathrm{He} \\
3-8 \% \mathrm{CO}_{2} \\
30-40 \% \mathrm{Ar}\end{array}$} & $\begin{array}{l}\text { Material: aço carbono. Melhorou a deposição sobre o metal base em virtude da } \\
\text { transferência metálica ser por spray. }\end{array}$ \\
\hline 1990 & [31] & \multicolumn{2}{|c|}{$\begin{array}{l}\mathrm{Ar} \\
0,5-1,25 \% \mathrm{CO}_{2} \\
30-40 \% \mathrm{He}\end{array}$} & $\begin{array}{l}\text { Material: aço carbono, aço inoxidável, metais não ferrosos. Produz uma solda com } \\
\text { aparência superior a obtida com outras misturas, com aspecto liso e com pouca ou } \\
\text { nenhuma oxidação, sem instabilidade do arco. A taxa de transferência metálica é } \\
\text { alta. }\end{array}$ \\
\hline
\end{tabular}




\begin{tabular}{|c|c|c|c|c|}
\hline 1991 & [32] & \multicolumn{2}{|c|}{$\begin{array}{l}20-65 \% \mathrm{Ar} \\
30 \% \mathrm{CO}_{2} \\
5-20 \% \mathrm{He}\end{array}$} & $\begin{array}{l}\text { Material: aço carbono. Com esta composição do gás de proteção é possível o uso } \\
\text { de correntes de até } 1000 \mathrm{~A} \text {, mantendo boa densidade e um formato satisfatório do } \\
\text { cordão. Com essas misturas houve baixa formação de respingos e liberação de } \\
\text { fumos. A melhor aparência da solda é obtida com correntes maiores que } 600 \mathrm{~A} \text {. }\end{array}$ \\
\hline 1996 & [33] & \multicolumn{2}{|c|}{$\begin{array}{c}\mathrm{Ar} \\
2-20 \% \mathrm{O}_{2}\end{array}$} & $\begin{array}{l}\text { Material: aço carbono, aço inoxidável. A adição de } \mathrm{O}_{2} \text { aumentou a taxa de } \\
\text { transferência metálica, que variou de acordo com a corrente utilizada, promovendo } \\
\text { a formação de um cordão de solda de melhor qualidade. }\end{array}$ \\
\hline 2001 & [34] & \multicolumn{2}{|c|}{$\begin{array}{l}96 \% \mathrm{Ar} \\
3 \% \mathrm{CO}_{2} \\
1 \% \mathrm{O}_{2}\end{array}$} & $\begin{array}{l}\text { Material: aço carbono, aço inoxidável. Obtem-se transferência metálica por } \\
\text { curto-circuito, por spray entre outras. Com esta composição não ocorre alteração } \\
\text { significativa da química do metal de solda. }\end{array}$ \\
\hline \multirow[b]{2}{*}{2002} & \multirow[b]{2}{*}{ [19] } & \multicolumn{2}{|c|}{$\mathrm{Ar}$} & $\begin{array}{l}\text { Material: aço carbono, aço inoxidável. O arco de soldagem apresenta-se } \\
\text { bastante instável. A solda não tem molhabilidade adequada e são produzidas } \\
\text { descontinuidades. }\end{array}$ \\
\hline & & \multicolumn{2}{|c|}{$\begin{array}{l}\mathrm{Ar} \\
\mathrm{CO}_{2} \\
\mathrm{O}_{2}\end{array}$} & $\begin{array}{l}\text { Material: aço carbono, aço inoxidável. } \mathrm{O}_{2} \text { melhora a fluidez, molhamento } \\
\text { e penetraça do cordão de solda. Além da estabilização do arco, as adições } \\
\text { progressivas contribuem para a perda de elementos de liga através do arco. Adições } \\
\text { de } \mathrm{CO}_{2} \text { aumentaram as emissões de fumos de soldagem. }\end{array}$ \\
\hline \multirow{2}{*}{2009} & \multirow{2}{*}{ [35] } & $\begin{array}{l}97.5 \% \mathrm{Ar} \\
2.5 \% \mathrm{CO}_{2}\end{array}$ & $\begin{array}{l}82 \% \mathrm{Ar} \\
18 \% \mathrm{CO}_{2}\end{array}$ & \multirow{2}{*}{$\begin{array}{l}\text { Material: aço carbono. Com o aumento da porcentagem de } \mathrm{CO}_{2} \text { no gás de proteção } \\
\text { verificou-se o aumento na penetração da solda e a diminuição na quantidade de } \\
\text { inclusões. }\end{array}$} \\
\hline & & $\begin{array}{l}90 \% \mathrm{Ar} \\
10 \% \mathrm{CO}_{2}\end{array}$ & $\begin{array}{r}75 \% \mathrm{Ar} \\
25 \% \mathrm{CO}_{2}\end{array}$ & \\
\hline 2009 & [23] & \multicolumn{2}{|c|}{$\begin{array}{c}\mathrm{Ar} \\
1 \% \mathrm{O}_{2}\end{array}$} & $\begin{array}{l}\text { Material: aço carbono. Em condições com baixa corrente o arco elétrico é instável, } \\
\text { com transferência metálica globular e grande formação de respingos. Nos períodos } \\
\text { de alta corrente, a transferência por spray foi estável, ocorrendo baixa formação de } \\
\text { respingos e um arco mais longo. O processo foi instável e após cerca de } 3 \text { a } 6 \mathrm{~s} \text {, } \\
\text { tornou-se estável. Esta transição foi caracterizada por um aumento no comprimento } \\
\text { do arco }(\text { de } 4 \mathrm{~mm}) \text { e da corrente (entre } 50-100 \mathrm{~A}) \text {. }\end{array}$ \\
\hline 1988. & [36] & \multicolumn{2}{|c|}{$\begin{array}{l}71-83 \% \mathrm{Ar} \\
16 \%-25 \% \mathrm{He} \\
1-4 \% \mathrm{CO}_{2}\end{array}$} & $\begin{array}{l}\text { Material: aço inoxidável, aços de baixa liga, ligas a base de Ni e metais não ferrosos. } \\
\text { Utilizando-se gás de proteção com esta composição a taxa de deposição de metal é } \\
\text { aumentada, com a entrada de energia reduzida, na soldagem por arco pulsado, em } \\
\text { operações de soldagem fora de posição. }\end{array}$ \\
\hline 1992. & [37] & \multicolumn{2}{|c|}{$\begin{array}{l}\mathrm{Ar} \\
0,1-0,9 \% \mathrm{CO}_{2} \\
5 \%-12 \% \mathrm{He}^{2}\end{array}$} & $\begin{array}{l}\text { Material: Super ligas a base de Ni, Co. Capacidade de soldar com uma grande } \\
\text { variedade de modos de transferência metálica com a estabilidade do arco excelente, } \\
\text { perfil do cordão e a aparência adequada. As características do arco são mantidas de } \\
\text { forma a não produzir oxidação excessiva do metal de solda. }\end{array}$ \\
\hline 2002 & [38] & \multicolumn{2}{|c|}{$\begin{array}{l}\mathrm{Ar} \\
0,01-1,80 \% \mathrm{O}_{2} \\
20-98,2 \% \mathrm{He}^{2}\end{array}$} & $\begin{array}{l}\text { Material: Al e suas ligas. Transferência por spray, sem corrente pulsada. Proporciona } \\
\text { uma elevada produtividade devido a velocidades de soldagem de } 110 \mathrm{~cm} / \mathrm{min} \\
\text { em corrente contínua e } 105 \mathrm{~cm} / \mathrm{min} \text { em corrente alternada. As juntas soldadas } \\
\text { apresentam um baixo nível de inclusões de alumina, e adequadas propriedades } \\
\text { mecânicas. }\end{array}$ \\
\hline 2007 & [39] & \multicolumn{2}{|c|}{$\begin{array}{l}\mathrm{Ar} \\
6-10 \% \mathrm{CO}_{2} \\
6-10 \% \mathrm{He}^{2}\end{array}$} & $\begin{array}{l}\text { Material: aço revestido, galvanizado e aço aluminizado. Obteve-se transferência } \\
\text { metálica por curto-circuito e por spray. Pode ser aplicada com posição de soldagem } \\
\text { horizontal ou plana. Promoveu menor quantidade de respingos e porosidade. } \\
\text { Cordão de solda com melhor aparência. }\end{array}$ \\
\hline 2010 & [40] & \multicolumn{2}{|c|}{$\begin{array}{l}\mathrm{Ar} \\
20-30 \% \mathrm{CO}_{2} \\
12-15 \% \mathrm{O}_{2}\end{array}$} & $\begin{array}{l}\text { Material: aço galvanizado. Na soldagem de ângulo, de uma folha, usando essa } \\
\text { composição do gás de proteção é possível obter uma velocidade de soldagem de } \\
\text { até } 125 \mathrm{~cm} / \mathrm{min} \text {. }\end{array}$ \\
\hline
\end{tabular}


De acordo com a Tabela 2 é possível verificar, de uma forma geral, que na maioria das composições de gás de proteção estudadas e patenteadas, o Ar e/ou o He são usados como gases predominantes, sendo usado o $\mathrm{CO}_{2}$, e o $\mathrm{O}_{2}$ para formarem misturas para a soldagem de diferentes classes de materiais. Pode ser observado que os teores nas diferentes composições não variam substancialmente. As faixas de composição previstas em algumas patentes são coincidentes. Destaca-se nos resultados, para as diferentes classes de materiais e composições do gás de proteção, a melhoria da estabilidade do arco, a diminuição dos respingos e a obtenção de soldas com bom aspecto visual e propriedades mecânicas adequadas.

$\mathrm{O}$ teor de $\mathrm{O}_{2}$ utilizado no gás de proteção para a soldagem de aços inoxidáveis está em intervalos próximos ao usado para a soldagem do aço carbono. Em geral nas patentes requeridas afirma-se que podem ser utilizadas as composições para soldagem de ambos materiais $[19,33,34]$. A porcentagem de $\mathrm{O}_{2}$ mais encontrada nas misturas é em torno de até 3\% [19,23,29,34,38].

$\mathrm{O}$ baixo percentual de $\mathrm{O}_{2}$ mostrado nas diferentes referências esta de acordo com a norma AWS A5.32 [26]. Esta específica que a porcentagem mais adequada deste gás para estabilizar o arco é de $1 \%$. Em aços inoxidáveis, com esta porcentagem de $\mathrm{O}_{2}$ em misturas com Ar, obtém-se uma taxa maior de transferência metálica, que ocorre por spray e torna a poça de fusão mais fluida. No entanto foi encontrado que é possível obter boas propriedades na solda depositada quando este gás está presente em misturas num teor maior $[27,33,40]$.

No que se refere às adições de $\mathrm{CO}_{2}$, o teor varia numa faixa de até $30 \%$. As porcentagens mais baixas são para as ligas de $\mathrm{Ni}$, e metais não ferrosos como o $\mathrm{Al}[31,36,37,38,39]$.

\section{Outros Gases Usados na Soldagem}

O predomínio dos gases que fornecem uma atmosfera ligeiramente oxidante também pode ser observado na norma AWS A5. 32 [26], pois nesta constam apenas o $\mathrm{N}_{2}$ e o $\mathrm{H}_{2}$ como gases diferentes dos já citados anteriormente. Foi identificado que o $\mathrm{H}_{2}, \mathrm{o}_{2}$ e o $\mathrm{NO}$ (óxido nítrico) foram utilizados em aplicações industriais. No entanto, também foram encontrados trabalhos utilizando adições de gases distintos dos mencionados acima, porém sem aplicação industrial.

\subsection{O uso de $\mathrm{H}_{2}$ no Gás de Proteção}

$\mathrm{O}_{2}$ é um exemplo de gás redutor que forma uma excelente atmosfera protetora por causa de sua capacidade de redução, sendo muito utilizado em fornos para tratamento térmico e em operações de brasagem. Em soldagem o uso do $\mathrm{H}_{2}$ é indesejável para certas aplicações, principalmente na soldagem do aço carbono, pois este gás é solúvel em certo grau em quase todos os metais, aumentando o risco de trincas a frio.

$\mathrm{O}$ fato do $\mathrm{H}_{2}$ ter uma condutividade térmica elevada torna o arco mais condutor durante a soldagem, aumentando assim a temperatura, o que pode favorecer a diminuição da dureza, pois torna mais longo o tempo de resfriamento [41]. Em contrapartida este gás proporciona uma maior penetração da solda. A superfície da solda produzida por adição de $\mathrm{H}_{2}$ ao $\mathrm{Ar}$ se mostra limpa e sem óxidos [9].

A adição de $\mathrm{H}_{2}$ ao Ar ou a misturas $\mathrm{Ar} / \mathrm{He}$ é empregada na soldagem de ligas de Al, aços inoxidáveis entre outras [19]. As misturas de $\mathrm{Ar} / \mathrm{H}_{2}$ são muito comuns na Europa, com teor de $\mathrm{H}_{2}$ na faixa de $2-5 \%$, para soldagem manual. A partir de $5 \%$ de $\mathrm{H}_{2}$ na mistura, a temperatura do processo fica muito elevada, o que requer operação de soldagem automática, onde se consegue obter um efeito perceptível no aumento da velocidade de soldagem [1].

Misturas comerciais de $\mathrm{Ar} / \mathrm{H}_{2}$ produzem uma atmosfera que reduz a oxidação na superfície do metal de solda durante a soldagem, sendo recomendados teores de no máximo $15 \%$ para soldagem de aços inoxidáveis [26].

$\mathrm{Na}$ soldagem MIG/MAG de ligas de alto níquel, como Inconel da série 625 e 600, as dificuldades são muitas vezes encontradas devido à lentidão da formação da poça de solda. Neste caso, a adição de $\mathrm{H}_{2}$ ao Ar, por produzir mais calor na poça de fusão, melhora a fluidez da solda [19]. Gás de proteção com $0,05-0,5 \% \mathrm{CO}_{2}$ e $0,1-7 \%$ de $\mathrm{H}_{2}$ para a soldagem de ligas de Ni foi estudado por Biskup [42], obtendo melhor estabilidade do arco e molhamento do cordão de solda. O arco mais estável torna mais concentrado o calor aumentando a penetração (profundidade), aumentando a velocidade de soldagem e reduzindo significativamente a oxidação da superfície dos cordões de soldagem, tornando dispensável operações pós soldagem.

$\mathrm{O}$ uso de $\mathrm{H}_{2}$ no gás de proteção também é recomendado na soldagem de ligas de $\mathrm{Cu}$ [43]. Este deve estar numa porcentagem entre $0,2-1 \%$ na mistura com $0,5-4 \%$ de $\mathrm{CO}_{2}$ e equilíbrio em $\mathrm{Ar}$, melhorando o acabamento do cordão de solda, a sua geometria e a soldagem produz menos respingos por ser obtida transferência metálica por spray.

Em contraste com dados mostrados na Tabela 2, para soldagem de aço galvanizado em que se utilizou gás de proteção com $\mathrm{O}_{2}$, na patente obtida por Macêdo e Correia [44] este gás é substituído pelo $\mathrm{H}_{2}$ na soldagem deste tipo de material. Consideram o $\mathrm{O}_{2}$ prejudicial, pois contribui para a oxidação do zinco, já que danifica a base do revestimento do metal, o que afeta a resistência à corrosão. Outra limitação destas misturas de $\mathrm{Ar} / \mathrm{O}_{2}$ é que a estabilidade do arco produzido pelas adições de oxigênio está limitada a um intervalo estreito de espessura do revestimento. A proposta é de uma mistura com $0,5-4 \% \mathrm{CO}_{2}, 0,2-$ $1 \% \mathrm{H}_{2}$ e equilíbrio de $\mathrm{Ar}$, onde se obteve a estabilidade do arco, que gera menos respingos, melhora a geometria e a aparência do cordão de solda. É requerida ainda a aplicação numa ampla faixa de espessuras de revestimento do metal de base, obtendose a manutenção da resistência à corrosão do material e melhor propriedades mecânicas da junta.

\subsection{O Uso de $\mathrm{N}_{2}$ e NO no Gás de Proteção}

A adição de $\mathrm{N}_{2}$ pode ser útil na proteção em soldagem, porém é utilizado em uma área limitada de operações. Embora $\mathrm{o}$ ataque do $\mathrm{N}_{2}$ sobre o ferro fundido não seja tão forte como o do ar, forma nitretos na superfície que se dissolvem, em certa quantidade, no metal fundido. $\mathrm{O} \mathrm{N}_{2}$ tem entalpia elevada, quando comparado ao $\mathrm{H}_{2}$, o que ocasiona transferência de mais calor 
para a poça de fusão na soldagem $\mathrm{MIG} / \mathrm{MAG}$, porém provoca a produção de poros. É considerado, em baixas temperaturas, como inerte para a soldagem do cobre $(\mathrm{Cu})$. Já na soldagem de ligas de alumínio (Al), magnésio (Mg) e titânio (Ti), deve ser utilizado em pequenas proporções na mistura com o Ar, pois reage com estes metais [11].

$\mathrm{Na}$ soldagem do aço inoxidável, o $\mathrm{N}_{2}$ é um elemento estabilizador da austenita, portanto diminui a tendência a formação de ferrita. Este também favorece as propriedades mecânicas e de resistência à corrosão. Além disso, pode durante um resfriamento rápido, como ocorre em soldagem, formar uma microestrutura muito fina (refinamento de grão). Foi atribuído a estas características do $\mathrm{N}_{2}$ a identificação de valores de dureza mais elevados na soldagem de aços inoxidáveis austeníticos, quando utilizado um gás de proteção com uma composição de $45 \% \mathrm{He}, 45 \%$ Ar e $10 \%$ de $\mathrm{N}_{2}$ [45]. Em testes com teor de $\mathrm{N}_{2}$ variando entre 2 e $10 \%$ no gás, foi verificado que quanto maior o teor de $\mathrm{N}_{2}$, menor é a formação de ferrita, maior a resistência a tração e a dureza, sendo mantida a resistência a corrosão $[46,47]$. Misturas com $\mathrm{N}_{2}$ e $\mathrm{H}_{2}$ no gás de proteção também se mostram adequadas para soldagem dos aços inoxidáveis [26].

Os aços inoxidáveis super austeníticos e superduplex são, em geral, ligados ao nitrogênio, e apresentam a formação de uma microestrutura que consiste de ferrita delta e austenita no metal de solda [46,47]. Quando o gás de proteção contém uma porcentagem de $\mathrm{N}_{2}$, as perdas deste elemento no metal de solda podem ser evitadas [48]. A adição de $\mathrm{N}_{2}$ ao gás de proteção é considerada adequada quando provoca a redução intencional da fase ferrita, como mostrado por Roualt [49] na soldagem TIG ou GTAW dos aços inoxidáveis duplex e superduplex. Utilizandose teores de 1 a $3 \%$ de $\mathrm{N}_{2}$ no gás de proteção associado a $\mathrm{Ar}$ e He, foi obtido um arco estável, o metal depositado apresentou boa resistência à corrosão, demonstrando ser apropriado para soldagem manual em todas as posições. De acordo com Kim [50] as soldas dessa classe de material, obtidas com a adição de $\mathrm{N}_{2}$ no gás de proteção, mesmo em ambientes com alta concentração de cloretos, tem a sua resistência a corrosão por pite aumentada.

A adição de NO ao Ar é usado para reduzir a emissão de ozônio próximo à operação de soldagem. O gás ozônio $\left(\mathrm{O}_{3}\right)$ é extremamente tóxico, pode causar severa irritação nos olhos e nas membranas mucosas. A redução de ozônio pode melhorar a qualidade do ambiente onde a soldagem é realizada. $\mathrm{O}$ princípio para o uso de NO no gás de proteção é que este reage com o ozônio produzido pela radiação do arco, neutralizando-o antes que este entre na zona de respiração do soldador [51].

Foi reportado por Dennis et al [51] que na soldagem do aço inoxidável pelo processo $\mathrm{MIG} / \mathrm{MAG}$, a adição de 0,03\% NO ao Ar produziu uma redução de até $60 \%$ na concentração de ozônio quando comparado com a mistura 93\% $\mathrm{Ar}, 2 \% \mathrm{O}_{2}$ e $5 \% \mathrm{CO}_{2}$. Estes autores também observaram uma redução de $70 \%$ na quantidade de $\mathrm{Cr}(\mathrm{VI})$ emitida. $\mathrm{O} \mathrm{Cr}(\mathrm{VI})$ é suposto ser elemento carcinogênico. Há também possíveis efeitos benéficos sobre concentração, produtividade, consistência e na qualidade da soldagem quando foram feitos ensaios com o gás NO. Este estabiliza o arco e tem um bom efeito na soldagem de aços inoxidáveis e do alumínio. A invenção de Selander [52] apresenta um método para reduzir durante a soldagem a formação de ozônio. A proposta é introduzir o gás $\mathrm{NO}, \mathrm{N}_{2} \mathrm{O}$ ou $\mathrm{NH}_{3}$ no gás de proteção em quantidades limitadas. Estes ajudam na decomposição de $\mathrm{O}_{3}$ em limites aceitáveis sem afetar a solda. A quantidade aceitável desses gases nas misturas deve ser inferior a $0,45 \%$.

\subsection{Gases Não Convencionais}

A adição de gases não convencionais nas misturas de gás de proteção, para soldagem de diferentes tipos de materiais é discutida neste item do trabalho. Em geral encontram-se associados a estudos científicos, com objetivos semelhantes aos já mencionados: melhorar as características tanto do processo de soldagem quanto da qualidade da solda.

$\mathrm{Na}$ soldagem do Al e suas ligas foi encontrada algumas misturas com gases não convencionais. Um método considerado como mais produtivo para soldagem do $\mathrm{Al}$ foi requerido em 1963 na patente de Wills [53], com adição de 0,05 a 3\% de $\mathrm{Cl}$ e balanço em Ar ou He. Como benefício, obteve-se a eliminação da porosidade e uma redução do custo com o gás de proteção. A adição do Cloro na soldagem do Al também foi estudada por Bicknell e Patchett [54], que utilizaram a adição de $0,75 \%$ de Cloro ao Ar verificando uma melhora significativa na estabilidade do arco e na penetração, quando a soldagem é feita com polaridade negativa. Como o uso do cloro, do ponto de vista da segurança, é altamente tóxico, foi sugerido como alternativa o uso de freons não-tóxicos (combinações de gases de $\mathrm{C}, \mathrm{F}, \mathrm{Cl}$ e $\mathrm{Br}$ ). Foram escolhidos quatro tipos de freons para realização de testes: Freon $12\left(\mathrm{CCl}_{2} \mathrm{~F}_{2}\right)$; Freon $13\left(\mathrm{CClF}_{3}\right)$; Freon 13-Bl $\left(\mathrm{CBrF}_{3}\right)$ e Freon $14\left(\mathrm{CF}_{4}\right)$. Como resultado obteve-se um aumento da intensidade do arco elétrico, quando $2,0 \%$ do Freon-12 foi adicionado ao gás de proteção.

A adição de 1 a $50 \%$ de hexafluoreto de enxofre $\left(\mathrm{SF}_{6}\right)$ e balanço de gás inerte também foi estudada para soldagem de ligas de Al. Esta mistura tem como benefício reduzir o $\mathrm{H}$ disponível para absorção na poça de solda por se ligar ao $\mathrm{SF}_{6}$, e pode ser utilizado nos processos de soldagem a arco [55].

$\mathrm{O}$ uso de neônio $(\mathrm{Ne})$, num teor de até $30 \%$ da quantidade de $\mathrm{He}$ (entre $20-90 \%$ ) na mistura, associado ao $\mathrm{H}_{2}(0,5-2 \%)$ foi estudado para soldagem de ligas de aço com estrutura austenítica ou do tipo duplex [56]. Com este gás de proteção se obtém na soldagem, transferência metálica tanto por spray quanto por curto-circuito. A poça de fusão formada é bastante fluida, o que torna inconveniente à soldagem em todas as posições.

Gases radioativos tais como o hidrogênio-3 e o criptônio-85, podem ser introduzidos ao gás de proteção $\mathrm{Ar}$ ou $\mathrm{He}$, visando ionizar o arco elétrico além de promover sua estabilidade. Vários tipos de gases radioativos podem ser utilizados de acordo com a patente requerida por Mathews [57], pois reduzem o tempo de abertura do arco, tornando-o mais uniforme. O tempo de abertura do arco inclui o tempo necessário para iniciar uma descarga elétrica e o tempo necessário para formar o arco.

Adições de pequenas concentrações de $\mathrm{SO}_{2}$ ao gás de proteção Ar, na soldagem de aços dissimilares é mostrada como responsável por melhorar drasticamente a relação entre a largura e a penetração da solda pelo processo GTAW, entre aços inoxidáveis e aços carbono. O benefício máximo da adição de 
$\mathrm{SO}_{2}$ foi alcançado com quantidades entre cerca de 500 e 1400 ppm. No entanto devem ser tomadas medidas adequadas de segurança já que o gás $\mathrm{SO}_{2}$ é tóxico [58].

Nos processos de soldagem que utilizam a proteção com os gases não convencionais destaca-se que os principais problemas que podem ocorrer estão relacionados com a segurança na operação de soldagem. São na maioria gases tóxicos, o que pode causar condições inapropriadas para os soldadores devido aos resíduos gerados. Pode ainda ser atribuído a esta toxicidade dos gases o direcionamento das aplicações a materiais e condições mais específicas que com os outros gases.

\section{Considerações finais}

O presente trabalho descreve a fenomenologia da proteção gasosa na soldagem, com ênfase no processo MIG/MAG e para a soldagem dos aços. Pode ser observado que o modelo oxidante de atmosfera gasosa predomina há mais de 30 anos nas misturas gasosas, as quais variam bastante, porém continuam sendo à base de $\mathrm{Ar}, \mathrm{He}, \mathrm{CO}_{2}$ e $\mathrm{O}_{2}$. Alguma aplicação foi observada para o $\mathrm{H}_{2}, \mathrm{o} 0 \mathrm{~N}_{2}$ e o $\mathrm{NO}$ (óxido nítrico) visando aplicações específicas. Poucos estudos foram identificados usando novos tipos de gases. Desta forma, foi observada pouca inovação no desenvolvimento de novas formulações de gases de proteção.

De fato, a inovação tem sido extensiva nos equipamentos de soldagem, capazes de controlar a transferência metálica. A tecnologia embutida no equipamento de soldagem torna-o capaz de modular o perfil da curva de corrente, obtendo efeitos distintos. O controle pode ter como objetivos: garantir uma transferência metálica mais uniforme, com melhoria do aspecto do cordão e menos respingos; uma pequena poça de fusão, para a soldagem de passe de raiz ou em chapas finas; obter uma relação penetração/taxa de deposição controlada, pela distribuição de calor entre eletrodo e metal base [11]. São exemplos destes avanços os processos MIG Pulsado, MIG Pulsado com Comando Sinérgico, MIG com pulsação térmica ou MIG Duplo Pulso, MIG com corrente alternada e MIG/MAG com curto-circuito controlado eletricamente e eletromecanicamente.

A tendência observada para o desenvolvimento de gases de proteção parece ser o uso de misturas ricas em gases inertes, com adições calibradas de elementos oxidantes, sempre atendendo a aplicações específicas. A pesquisa continuará no sentido de aumentar a taxa de deposição, reduzir os respingos e melhorar a soldabilidade por meio dos gases de proteção.

\section{Agradecimentos}

Os autores agradecem à FAPERJ e ao $\mathrm{CNPq}$ por auxílios concedidos.

\section{Referências Bibliográficas}

[1] IRVING, B. Shielding Gases are the Key to Innovations in Welding. Welding Journal, v. 78, n. 1, p. 37-41, 1999.

[2] MODENESI, P.J. Introdução à Física do Arco Elétrico e sua Aplicação na Soldagem dos Metais. Universidade Federal de Minas Gerais, Departamento de Engenharia Mecânica, Apostila do Programa de Pós-Graduação em Engenharia Metalúrgica. Belo Horizonte. 158 p., 2009.

[3] MARQUES, P.V.; MODENESI, P.J.; VALENTE, O.B. Características do Arco de Soldagem TIG em Diferentes Atmosferas. IN: Encontro Nacional de Tecnologia de Soldagem, 24, 1998, Fortaleza. Anais... Fortaleza: Associação Brasileira de Soldagem, 1998.

[4] LANCASTER, J.F. The Physics of Welding. Oxford: Pergamon Press. London. 2 Ed. 340 p., 1996.

[5] MACHADO, I. G. Soldagem \& Técnicas Conexas: Processos. Porto Alegre: Editado pelo autor, 477 p., 1996.

[6] ATKINS, P.W.; JONES, L. Chemistry - Molecules, matter and change. 1997. New York: W.H. Freeman.

[7] LOWE, J.P. Entropy: Conceptual disorder. J. Chem. Educ., v. 65, n. 5, p. 403-406, 1988.

[8] LINNERT, G.E. Welding Metallurgy: Carbon and Alloy Steels. Fundamentals, 4th ed. American Welding Society (AWS). Miami, Florida, USA., 940 p., 1994.

[9] SUBAN, M.; TUSEK, J. Dependence of Melting Rate in MIG/MAG Welding on the Type of Shielding Gas Used. Materials Processing Technology, n. 119, p. 185-192, 2001.

[10] SCHWEDERSKY, M.B. et al. Soldagem TIG de Elevada Produtividade: Influência dos Gases de Proteção na Velocidade Limite para Formação de Defeitos. Soldagem e Inspeção, v. 16, n. 34, p. 333-340, 2011.

[11] SCOTTI, A.; PONOMAREV, V. Soldagem MIG/MAG: melhor entendimento, melhor desempenho. 284 p., 2008. São Paulo: Artliber Editora.

[12] LYTTLE, K.A.; STAPON, W.F.G. Select the Best Shielding Gas Blend for the Application. Welding Journal, v. 69, n. 11, p. 21-27, 1990.

[13] UMEHARA, Y.; SUZUKI, R.; NAKANO, T. Development of innovative GMAW wire with improved flowing characteristics of molten pool. IIW Doc. XII-1947-08, 1947.

[14] STENBACKA, N.; PERSSON, K.A. Shielding Gases for Gas Metal Arc Welding. Welding Journal, v. 68, n. 11, p. 41-47, 1989.

[15] NOVOZHILOV, N.M. Fundamental Metallurgy of Gas Shielded Arc Welding. Gordon and Breach Science Publishers S. A. Amsterdam. 400 p., 1988.

[16] AWS. Welding Handbook: Welding Processes. American Welding Society, v. 2. 8th ed. Miami, 955 p., 1991.

[17] SOUZA, D. et al. Influência da Tensão de Soldagem e do Gás de Proteção sobre a Correlação entre Indutância e Regularidade da Transferência Metálica na Soldagem MIG/MAG por CurtoCircuito. Soldagem e Inspeção, v. 16, n. 2, p. 114-122, 2011.

[18] FILHO, D. F., BALSAMO, P. S. S., FERRARESI, V. A. Influência do Tipo de Gás de Proteção da Soldagem MIG/MAG na Qualidade do Cordão de Aço Inoxidável; http://www.grima. ufsc.br/cobef4/files/ 021008077.pdf em 03/08/2012 página mantida pela GRIMA - UFSC.

[19] VAIDYA, V.V. Shielding Gas Mixtures for Semiauttomatic Welds. Welding Journal, v. 81, n. 9, p. 43-48, 2002.

[20] JARDIM, W.F.; CANELA, M.C. Fundamentos da oxidação química no tratamento de efluentes e remediação de solos. Universidade Estadual de Campinas - UNICAMP, Instituto de Química - IQ, Laboratório de Química Ambiental - LQA. 
Caderno Temático, vol. 1, Campinas - SP, 2004.

[21] DALPIAZ, 1999 DALPIAZ, G.; MACHADO, I.G. Efeito do Helio em gases de proteção com Ar-CO2 e Ar-O2 na soldagem MAG com corrente pulsada. Soldagem \& Inspeção, São Paulo, v. 5, n. 8, p. 7-16, 1999.

[22] MOREIRA, A.F. Influência da atmosfera protetora no cordão de solda obtido através dos processos de soldagem GMAW e FCAW. Tese (Mestrado em Engenharia Mecânica) Ilha Solteira - SP, Faculdade de Engenharia - UNESP, 146 p., 2008.

[23] COSTA, M.C.M.S.; STARLING, C.M.D.; MODENESI, P.J. Low oxidation potential shielding gas instability in GMA welding. Science and Technology of Welding and Joining, v. 14, n. 1, p. 42-51, 2009.

[24] KOOISTRA, L.F. Metallic Arc Welding With Stabilized Inert Gas Shielding. Int. CI. 219-74. US 2,932,721. 14 fev. 1952, 12 abr. 1960.

[25] CHANG, Y.H. Improve GMAW and GTAW with Alternating Shield Gases. Welding Journal, v. 85, n. 2, p. 41-43, 2006.

[26] AWS A5.32M. Welding Consumables - Gases and Gas Mixtures for Fusion Welding and Allied Processes

2nd ed. American Welding Society. 2011.

[27] WOLFF, L.; MANTEL, W. Protective gas mixture for light arc welding with a fusible blank were electrode. Int. CI. 219 74. US 3,139,506. 14 abr. 1961, 30 jun. 1964.

[28] LESNEWICH, A. et al. Gas shielded arc welding of steel. Int. CI. B23k 9/16, 35/38, 9/00. US 3,496,323. 20 dez. 1965, 17 fev. 1970.

[29] HILTON, D.E. Shielding gas for electric arc welding. Int. C.I. B23K 9/00; B23K 35/38. US 4,626,646. 30 nov. 1983, 2 dez. 1986.

[30] LARSON, N.E.; LETURNO, D.B.; CHERNE, L.W. Spray mode gas metal arc welding process. Int. C.I. B23K 9/00. US 4,857,692. 17 ago. 1988, 15 ago. 1989.

[31] EVANS, J.R; COLVIN, E.D. Gas metal arc welding and shielding gas therefor. Int. CI. B23K 9/173. 14 fev. 1990, 27 nov. 1990 .

[32] SCHULTZ, J.P.; SOLER, J.; NICOUD, D. Gas mixture and welding method. Int. C.I. B23K 9/173. US 4,999,474. 27 mar. 1990, 12 mar. 1991.

[33] BREYMEIER R.T. Oxy-argon gas-shielded metal-arc welding. Int. CI. 219 - 74. US 3,253,113. 25 nov. 1964, 24 maio 1966.

[34] GAULT, J.T. Universal shielding gas for GMAW and FCAW welding and process. Int. CI. B23K 9/173. US 6,303,891 B1. 28 out. 1999, 16 out. 2001.

[35] EBRAHIMNIA, M. et al. Study of the effect of shielding gas composition on the mechanical weld properties of steel ST 37-2 in gas metal arc welding. Materials and Design, v.30, p. 3891-3895, 2009.

[36] GALANTINO, C.; VIRI, D.P.; VIRI, M.D. Pulsed arc welding method, apparatus and shielding gas composition. Int. CI. B23K9/16. US 4,749,841. 2 fev. 1987, 7 jun. 1988.

[37] HOBACK, G.L.; MEYERS, J.L. Shielding gas mixture for welding superalloys. Int. CI. B23K 9/16. US 5,083,002. 10 jan. 1991, 21 jan 1992.

[38] FORTAIN, J.M. et al. Process for the MIG welding of aluminum and its alloys with a shielding gas of the $\mathrm{Ar} / \mathrm{He} / \mathrm{O} 2$ type. Int. C.I B23K 9/173. US 2002/0036186 Al. 22 jun. 2000, 28 mar. 2002.

[39] NEFF, J.; LYTTLE, K. Gas metal arc welding of coated steels and shielding gas therefor. Int. CI. B23K 9/173. US 7,161,109 B2. 17 jun. 2004, 9 jan. 2007.

[40] WADA, K.; KAMEI, T. Shielding gases for mag-welding of galvanized steel sheets and welding method using the same. Int. CI. B23K 9/16. US 7,718,915 B2. 22 out. 2007, 18 maio 2010.

[41] GÜLENÇ, B. et al. Experimental study of the effect of hydrogen in argon as a shielding gas in MIG welding of austenitic stainless steel. International Journal of Hydrogen Energy, v. 30, p. 1475-1481, 2005.

[42] BISKUP, L. et al. Process for the MIG welding of nickeland nickel alloys with a shielding gas based on argon and $\mathrm{CO}_{2}$. Int. CI. B23K 9/173. US 6,596,971 B1. 6 set. 2001, 22 jul. 2003.

[43] CORREIA, J.V.O.; COSTA, J.F.M. Shielding gas mixture for MIG brazing. Int. C.I. B23K 1/00; B23K 35/37. US 6,570,127 B2. 3 maio 2001, 27 maio 2003.

[44] MACÊDO, W. A; CORREIA, V. O. Gas Composition For Arc Welding. Int. CI. B23K 9/173. US 7,071,438 B2. 7 Mar. 2003, 4 jul. 2006.

[45] SATHIYA, P.; MISHRA, M.K.; SHANMUGARAJAN, B. Effect of shielding gases on microstructure and mechanical properties of super austenitic stainless steel by hybrid welding. Materials and Design, v. 33, 203-212, 2012.

[46] LIN, Z. et al. Influence of Nitrogen and Heat Input on Weld Metal of Gas Tungsten Arc Welded High Nitrogen Steel. Journal of Iron and Steel Research, International, v. 14, n. 5, Supplement 1, p. 259-262, 2007.

[47] HUANG, H.Y. Effects of shielding gas composition and activating flux on GTAW weldments. Materials and Design, v. 30, p. 2404-2409, 2009.

[48] MOYER, N. The evolution of shielding gas. Welding Journal, v. 76, p. 51-52, 2002.

[49] ROUAULT, P.; DIOT, H. Shielding gas mixture and process for arc welding of stainless steel workpieces. Int. CI. B23K 9/167. US 5,739,503. 19 mar. 1996, 14 abr. 1998.

[50] KIM, S.T. et al. Effects of solution heat-treatment and nitrogen in shielding gas on the resistance to pitting corrosion of hyper duplex stainless steel welds. Corrosion Science, v. 53, p. 1939-1947, 2011.

[51] DENNIS, J.H. et al. Control of Exposure to Hexavalent Chromium and Ozone in Gas Metal in Gas Metal Arc Welding of Stainless Steels by Use of a Secondary Shield Gas. The Annals of Occupational Hygiene, v. 46, n. 1, p. 43-48, 2002.

[52] SELANDER, L.; FAHLÉN, L.; SIPEK, L. Method for decomposing ozone. Int. CI. B23K 9/16. US 4,292,493. 5 jul. 1979, 29 set. 1981.

[53] WILLS, K.L. Welding Method. Int. C.I. 219-74. US 3,102,188. 12 ago. 1959, 27 ago. 1967.

[54] BICKNELL, A.C.; PATCHETT, B.M. GMA Welding of Aluminum with Argon/Freon Shielding Gas Mistures. Welding Journal, v. 64, n. 5, p. 21-27, 1985.

[55] TUTLE, W.H. Method of welding material with reduced porosity. Int. CI. B23K 9/167. US 2007/ 0045238 A1. 29 ago. 
2005, 1 mar. 2007.

[56] DUBOZ, G.; DEMARS, P. Protective atmosphere for the arc welding and surfacing of steels. Int. CI. HO 5b 11/00. US 3,470,346. 23 maio 1966, 30 set. 1969.

[57] MATHEWS, H.H. ARC WELDING. Int. CI. 219-74. US 3,089,944. 6 nov. 1959,14 maio de 1963.

[58] HEIPLE, R.C.; BURGARDT, P. Effects of $\mathrm{SO}_{2}$ shielding gas additions on GTA weld shape. Welding Journal Research Supplement, v. 64, n. 6, p. 159s-162s, 1985. 